\title{
Evolución de la teoría del delito
}

\section{Evolution of the theory of crime}

\author{
Kendy Marisol Pérez Arreaga \\ Maestría en Derecho Penal \\ Universidad de San Carlos de Guatemala \\ Kendyp19@gmail.com
}

Recibido: 29/06/2021

Aceptado: 15/08/2021

\section{Referencia del artículo}

Pérez Arreaga, K. M. (2021). Evolución de la teoría del delito. Revista Diversidad Científica, 1(1). 97-104.

\section{DOI: https://doi.org/10.36314/diversidad.v1i1.11}

\section{Resumen}

El trabajo de investigación nos permite identificar cómo se ha considerado la teoría del delito de conformidad con cada etapa histórica y según sus propulsores, es decir, que se analiza la evolución que ha tenido el concepto de delito, desde ser considerado un acto, un hecho, un acto, un comportamiento humano, inclusive una finalidad, pertenencia a un grupo delictivo. Reviste importancia derivado que representa una parte de la ciencia del derecho penal que busca definir si una conducta humana puede ser considerada o no un delito.

Palabras clave: delito, teoría, derecho penal, evolución 


\begin{abstract}
The research work allows us to identify how the theory of crime has been considered in accordance with each historical stage and according to its promoters, that is, the evolution that the concept of crime has had is analyzed, from being considered an act, a fact, an act, a human behavior, even a purpose. It is of derived importance that represents a part of the science of criminal law that seeks to define whether or not human conduct can be considered a crime.
\end{abstract}

Keywords: crime, theory, criminal law, evolution 


\section{Introducción}

Desde tiempos remotos se ha definido al delito de forma generalizada como una conducta típica, antijurídica y culpable, en cada país se puede definir de forma distintita atendiendo a su legislación, pero en su mayoría se adopta la teoría del delito para buscar resolver casos concretos y reprochar penalmente las conductas prohibidas, lo que se pretende es evidenciar la evolución que ha tenido la teoría del delito de acuerdo a lo que han sostenido diferentes autores según sus postulados jurídicos.

\section{Contenido}

El concepto "delito" se ha ido desarrollando a través de los tiempos, los autores se han basado en diferentes ideas políticas, filosóficas y culturales para definirlo, existiendo así una variedad de corrientes que han explicado esta parte de la ciencia del derecho penal conocida como Teoría del Delito para aplicar la ley según corresponde en cada caso concreto.

Los alemanes empezaron a construir un concepto jurídico del delito y le denominan teoría general del delito. Existe un sinfín de perspectivas de esta parte del derecho penal, pero en general buscan determinar frente a una conducta si la misma puede ser delictiva o no, visualizando una posible sentencia (Zaffaroni, 2012: 24).

\section{Definiciones Generales}

Para entender la esencia y naturaleza de la teoría del delito es preciso definir algunos conceptos fundamentales:

\subsection{Derecho Penal}

El autor Francisco Vasconcelos lo define como las disposiciones jurídicas del derecho propio de cada ordenamiento, que nos proporciona las conductas que son consideradas delitos y su correspondiente pena o inclusive la aplicación de medida 
de seguridad con el objetivo de mantener la paz y orden dentro de una sociedad (Martínez, 2015: 2).

Para Francisco Von Liszt el derecho penal es un conjunto de reglas legales creadas por el Estado, que regulan el crimen como un hecho y la pena como una consecuencia jurídica (Liszt, 1909: 5).

\subsection{Teoría del Delito}

Representa una parte de la ciencia del derecho penal que se encarga de analizar cuáles son los elementos o características que deben concurrir en una conducta para que ésta sea considerada como delito.

Es un conjunto de lineamientos debidamente ordenados que establecen la integración o desintegración de una acción humana que es contemplada como delito por parte de la ley.

Muñoz Conde al respecto la define como un "sistema categorial clasificatorio y secuencial en el que, peldaño a peldaño, se van elaborando, a partir del concepto básico de la acción, los diferentes elementos esenciales comunes a todas las formas de aparición del delito". (Muñoz Conde \& García Arán, 2004: 205).

Es una teoría de imputación que, a través de la identificación de los distintos elementos que en el derecho penal vigente convierten un determinado hecho en un delito, permite la imputación del mismo a una persona para hacerla responsable del mismo. (Muñoz Conde \& García Arán, 2010: 45)

La teoría del delito constituye el instrumento mediante el cual se analizan las características que debe tener cualquier conducta realizada por una persona para ser considerada un delito (Muñoz Conde \& García Arán, 2010: 201).

\section{Evolución de la Teoría del Delito}

El autor Durkheim consideraba que el delito cumplía la función social positiva de provocar un rechazo y con eso reforzar la cohesión de la sociedad, es decir, que 
no pensaba que el crimen fuese positivo sino la reacción social que ese crimen provocaba, por lo que despatologizaba el delito y lo consideraba algo normal dentro de la sociedad (Zaffaroni, 2012: 127).

Existen dos corrientes principales que nos proporcionan lo que debe entenderse por delito, conocidas como teoría causalista y teoría finalista, constituyen sistemas que pese a considerar el delito como una conducta típica, antijurídica y culpable, nos brindan otros elementos que deben ser analizados para sancionar penalmente a una persona por una conducta.

\subsection{Teoría del Causalismo Naturalista}

Sus propulsores son Franz Von Liszt y Ernst Von Beling, en esta teoría se concibe la acción desde la perspectiva física o naturalística, integrada por un movimiento corporal y el resultado de una modificación en el mundo exterior, unidos por un nexo causal. Según esta teoría el delito se compone de dos fases: una interna y otra externa, la primera se da a través del pensamiento, mientras que en la segunda se ejecuta o consuma el delito, es decir, se lleva a cabo la idea que se origina en la fase interna (Peña Gonzáles \& Almanza Altamirano, 2010: 22).

En esta teoría se explica el delito en función con la naturaleza, porque todo es una relación de causa y efecto, la acción es considerada un fenómeno causal y/o natural que trae como consecuencia un resultado que puede ser o no un delito.

\subsection{Teoría del Finalismo}

Esta teoría nace con Welzel, se analiza el término finalidad y se determina que la acción como elemento del delito es una actividad final humana y no causación de resultado, lo que significa que la causalidad es ciega y la finalidad es vidente. La finalidad consiste en una sobredeterminación de la causalidad por la voluntad, que significa que en la dirección consciente del curso causal hacia una meta u objetivo previamente propuestos por la voluntad (Peña Gonzáles \& Almanza Altamirano, 2010: 39).

En esta teoría se considera que la acción es un comportamiento humano pero sometido a la voluntad y que se dirige hacia un resultado determinado, por lo que po- 
Revista Diversidad Científica Vol. 1 No. 1 Año 2021

dríamos establecer que esta teoría contempla al delito vinculado con el dolo como un requisito fundamental para su consumación.

\section{Conclusión}

La historia nos demuestra que en las diferentes etapas o épocas de la humanidad se ha tenido una idea distinta de lo que es el delito, concepto que ha ido evolucionando conforme a los autores, acontecimientos sociales, políticos, históricos e inclusive fenómenos de criminalidad organizada, genero entre otros que lo han considerado.

Dos son las corrientes filosóficas que más han sobresalido: teoría finalista y la teoría causalista, la última establece la acción como una relación de causa y efecto, mientras que la teoría finalista analiza que la acción es una actividad final humana y por tanto conlleva el dolo como presupuesto fundamental para que se cometa el delito.

La teoría del delito ha evolucionado en la perspectiva del delito, considerándolo un hecho, acto, conducta, comportamiento humano y actualmente el querer o pertenecer a un grupo delictivo como el derecho penal del enemigo.

La teoría del delito no escapa entonces a redefinirse de acuerdo al tiempo, la sociedad y la evolución del fenómeno delictivo.

\section{Declaración}

El estudio se realizó de acuerdo al Código de Ética y Buenas Prácticas COPE.

\section{Conflicto de intereses}

La autora declara no tener ningún conflicto de intereses. 


\section{Referencias}

Martínez, A. T. (2015). Teoría del delito y juicio oral. México: Instituto de Investigaciones Jurídicas de la UNAM.

Muñoz Conde, F., \& García Arán, M. (2004). Derecho penal. Parte general. Valencia, España: Tirant lo Blanch.

Muñoz Conde, F., \& García Arán, M. (2010). Derecho penal. Parte general. Valencia, España: Tirant lo Blanch.

Peña Gonzáles, O., \& Almanza Altamirano, F. (2010). Teoría del Delito. Manual práctico para su aplicación en la teoría del caso. Perú: Nomos \& Thesis E.I.R.L.

Von Liszt, F. (1909). Tratado de derecho penal. Madrid, España: Reus.

Zaffaroni, E. R. (2012). La Cuestión Criminal. Buenos Aires, Argentina: Planeta.

\section{Sobre la autora}

Kendy Marisol Pérez Arreaga

Licenciada en Ciencias Jurídicas y Sociales, Abogada y Notaria, egresada del Centro Universitario de Oriente -CUNORI- de la Universidad de San Carlos de Guatemala, con Maestría en Derecho Penal, ha realizado investigaciones sobre los gastos post mortem como extraordinarios en la regulación del derecho de alimentos, tesis impresa en septiembre de 2016, así como la vulneración del derecho a la libertad en la etapa de impugnaciones del proceso penal en Guatemala, tesis impresa en septiembre de 2020. 


\section{Copyright (c) Kendy Marisol Pérez Arreaga}

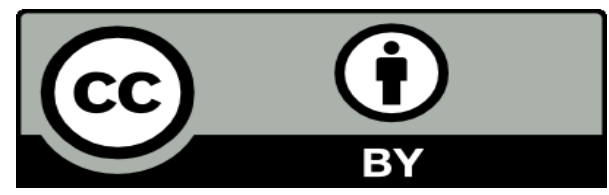

Este texto está protegido por una licencia CreativeCommons 4.0.

Usted es libre para compartir, copiar y redistribuir el material en cualquier medio o formato y adaptar el documento, remezclar, transformar y crear a partir del material para cualquier propósito, incluso comercialmente, siempre que cumpla la condición de atribución: usted debe reconocer el crédito de una obra de manera adecuada, proporcionar un enlace a la licencia, e indicar si se han realizado cambios. Puede hacerlo en cualquier forma razonable, pero no de forma tal que sugiera que tiene el apoyo del licenciante o lo recibe por el uso que hace. 